\title{
Comparison of Axillary Exclusion Versus no Exclusion on Seroma Formation after Modified Radical Mastectomy
}

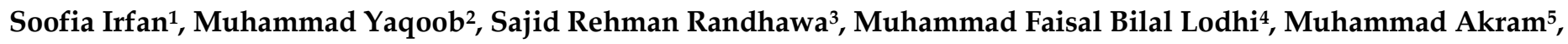 \\ Maham Mansoor ${ }^{6}$
}

1 Assistant Professor, Department of Surgery, Faisalabad Medical University, Faisalabad Pakistan
Author

2 Assistant Professor, Department of Surgery, Faisalabad Medical University, Faisalabad Pakistan

2 Co-Author

3 Associate Professor, Department of Surgery, Faisalabad Medical University, Faisalabad Pakistan

3 Co-Author

4 Professor, Department of Surgery, Faisalabad Medical University, Faisalabad Pakistan

4 Co-Author

5 Professor, Department of Surgery, Faisalabad Medical University, Faisalabad Pakistan

5 Co-Author

6 Post Graduate Resident, Department of Surgery, Allied Hospital, Faisalabad Pakistan

Co-Author

CORRESPONDING AUTHOR

Dr. Soofia Irfan

Assistant Professor, Department of Surgery,

Faisalabad Medical University, Faisalabad Pakistan

Email: surgicalu.3@gmail.com

Submitted for Publication: 24-09-2020

Accepted for Publication 08-03-2021

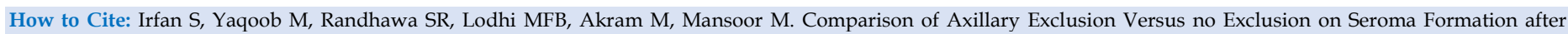
Modified Radical Mastectomy. APMC 2021;15(1):32-5. DOI: 10.29054/APMC/2021.1034

\section{ABSTRACT}

Background: Accumulation of seroma in axilla and under mastectomy flaps is a common side effect after axillary lymph nodes dissection in mastectomy, which requires repeated aspirations and prolonged stay of the drain causing discomfort to person. Objective: To determine the effectiveness of axillary exclusion technique versus no axillary exclusion in Modified Radical Mastectomy in terms of mean drain output. Study Design: Randomized control trial. Settings: The study was conducted in department of Surgery, Allied Hospital Faisalabad Pakistan. Duration: 1 year from August 08, 2018 to August 07, 2019. Methodology: After permission from Hospital Ethical Review Committee, 60 Patients presenting for mastectomy were included in the study. They were randomly divided into two equal groups of 30 patients each applying computer generated random number table. Group A (underwent axillary exclusion) and Group B (did not undergo axillary exclusion) after modified radical mastectomy. Total amount of fluid collected in drain bag postoperatively was noted till the removal of drain and compared between the groups. Data was entered in a pre-designed proforma. Results: Comparison of axillary exclusion technique with no exclusion after modified radical mastectomy was done, it showed that the mean of the total drain output $( \pm \mathrm{SD})$ in Group A was $1112.4 \mathrm{ml}( \pm 66.78)$ whereas mean output in Group-B was $2184 \mathrm{ml}( \pm 117.06)$. (Table No.1). p-value was $<0.001$ showing a considerable decrease in the total volume of the seroma fluid drained between the two groups. Conclusion: Study concluded that the axillary exclusion technique significantly reduces drain output in patients following modified radical mastectomy as compared to those who do not undergo axillary exclusion.

Keywords: Breast cancer, Modified radical mastectomy, Axillary exclusion, Drain output.

\section{INTRODUCTION}

In Pakistan, breast cancer has been found as the commonest cancer and is claimed to account for $34.6 \%$ of total cancer cases in women. ${ }^{1}$ The prevalence of breast cancer among women in Karachi South is the second highest in Asia. ${ }^{2}$ Majority of patients present in advanced stage. ${ }^{17}$ Surgery is the mainstay of treatment and modified radical mastectomy is the commonest procedure. The commonest reasons of morbidity following MRM are hematoma formation, wound infection and the formation of a seroma. ${ }^{4}$

Seroma occurs in $15-81 \%$ of patients following axillary dissection ${ }^{5}$. It is an observation that following MRM immediate breast reconstruction causes decreased seroma formation in comparison to cases where reconstruction performed later on. ${ }^{6}$ However, there is no variation found in seroma formation whether pectoral fascia is removed or preserved. ${ }^{7}$ Seroma requires to be aspirated repeatedly and increases the chances of wound infection and disruption, prolonged pain, reduced arm mobility and delayed recovery, impairing the quality of life. However, keeping the drain for longer also causes discomfort to the patients, though it is essential to drain the seroma. ${ }^{8}$ Axillary exclusion is a procedure devised to obliterate dead space thereby excluding axilla from the rest of wound after axillary clearance and leading to minimize collection. ${ }^{9}$ In this technique we apply continuous stitches with vicryl $2 / 0$ between the mastectomy skin flap and the lateral margin of pectoralis major, and place few interrupted sutures between 
pectoralis major and minor and the flap to separate the axillary space from the rest of the mastectomy wound and obliterate the dead space so created after axillary clearance. A pressure dressing is applied over axilla and also the mastectomy wound. $16 \mathrm{~F}$ Vaccum suction drain is placed with the tip placed within the wound under the skin flaps, and total volume of fluid drained is recorded. ${ }^{10}$

\section{METHODOLOGY}

Study Design: Randomized control trial.

Settings: Department of General Surgery, Allied Hospital, Faisalabad Pakistan.

Duration: 1 year from August 08, 2018 to August 07, 2019.

Sample Technique: Non-probability consecutive sampling.

Sample Size: By using WHO sample size calculator

Sample size $=60$ (30 in each group)

Inclusion Criteria: Patients with diagnosed stage II or III breast carcinoma having no distant metastasis and planned for mastectomy and female patients aged between 20-70 years.

Exclusion Criteria: Patients with history of previous breast surgery, chemotherapy or breast irradiation, patients having co-morbid factors like morbid obesity, poorly controlled diabetes and hypertension, patients arranged for conservative breast surgery or palliative surgery (for advanced breast cancer), patients with known collagen disease or diffuse small vessel disease and patients with a history of long-term use of steroids or with deranged clotting profile.

Data Collection Procedure: After getting approval from ethical review committee of hospital, 60 patients included in the study were admitted in General Surgery Department from outdoor of Allied Hospital Faisalabad. Written informed consent was obtained. They were randomly divided into two equal groups, Group A (underwent axillary exclusion) and Group B (did not undergo axillary exclusion) of 30 patients each by utilizing computer generated random number table.

In Group A modified radical mastectomy was done, hemostasis secured, axillary exclusion was done by suturing mastectomy flap to lateral margin of pectoralis major and lateral chest wall with vicryl $2 / 0$ and by interrupted sutures between pectoralis minor and major muscles. 16F closed suction drain was placed in mastectomy cavity. In Group B (control) mastectomy was done in same manner but axillary exclusion was not done, instead flaps were simply closed by inverted stitches of vicryl $2 / 0$ at the edges and skin staplers applied. one vaccum suction drain was placed.

In the postoperative period all the patients were observed for amount of fluid drained till the removal of drain. Drain was removed when fluid drainage ceased to $30 \mathrm{ml}$ in last 24 hours. Patients were discharged on second postoperative day mostly with instructions for drain care at home, followed by regular visits in surgical OPD for recording of total drain output before removing the drain. Data was entered in a pre-designed proforma attached. Data Analysis: All the data was transferred to SPSS version 20 and analyzed accordingly. Independent sample t-test was applied. P-value $<0.05$ decided to be considered significant.

\section{RESULTS}

A total of 60 cases (30 in each group) according the inclusion/exclusion criteria were enrolled to compare axillary exclusion versus no exclusion after modified radical mastectomy in terms of mean drain output.

Comparison of axillary exclusion technique with no exclusion after modified radical mastectomy was done, it showed that the mean of the total drain output $( \pm S D)$ in Group A was 1112.4.2ml ( \pm 86.78$)$ and whereas in GroupB was $2184.2 \mathrm{ml}( \pm 140.06)$. p-value was $<0.001$ showing a considerable reduction in the total volume of the seroma fluid drained between the two groups. (Table No.1)

Table 1: Comparison of total drain output in two groups $(\mathrm{n}=60)$

\begin{tabular}{|c|c|c|c|c|}
\hline \multirow{2}{*}{ Groups } & \multicolumn{3}{|c|}{ Total Drain Output } & \multirow{2}{*}{ P-Value } \\
\cline { 2 - 4 } & Mean (ml) & +SD & Range (ml) & \\
\hline $\begin{array}{c}\text { Group A } \\
\text { (n=30) }\end{array}$ & 1112.4 & 86.78 & $920-1320$ & \\
\hline $\begin{array}{c}\text { Group B } \\
\text { (n=30) }\end{array}$ & 2184.2 & 140.06 & $1300-2500$ & \multirow{2}{*}{0.00078} \\
\cline { 1 - 4 } Total & 1648.3 & 117 & $920-2500$ & \\
\hline
\end{tabular}

In group A we could remove the drain of (90\%) 27 patients within 7 days and rest 3 patients (10\%) within 14 days. In Group B only 6 patients $(20 \%)$ drains were removed on day 7 , in 27 patients $(70 \%)$ on day $14 \&$ in 3 patients $(10 \%)$ on day 18.

Figure 1: Duration of drain placement

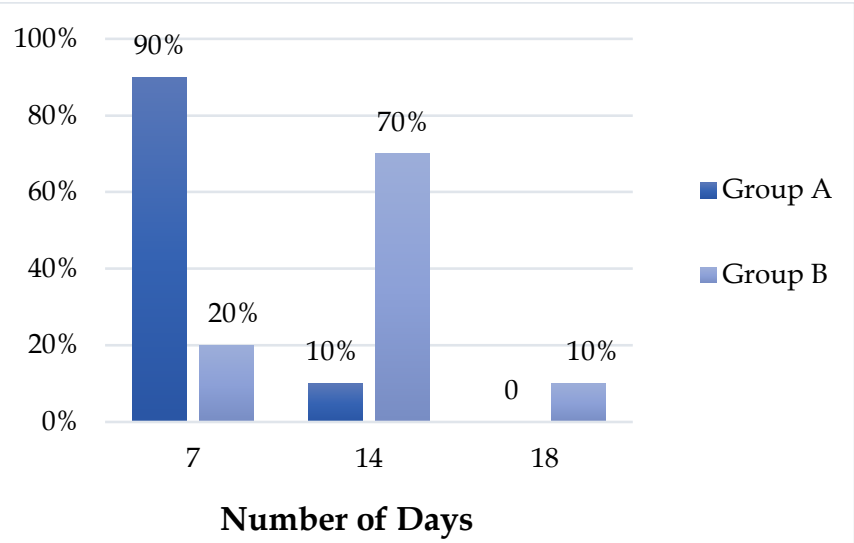

\section{DISCUSSION}


A seroma is a collection of serous fluid that accumulates under the skin flaps or in the axillary dead space and is a common sequel following mastectomy. Seroma and its consequences form the mainstay of complications in breast cancer surgery, varying from increased susceptibility to infection, skin flap necrosis, persistent pain and wound dehiscence. Prolonged stay of the drain needed to drain seroma fluid is also a frequent cause of discomfort for the patient.

This study was planned to find out a better surgical technique to lessen the psychological and financial burden of seroma.

Comparison of axillary exclusion technique with no exclusion after modified radical mastectomy was done. It showed that the mean $( \pm S D)$ of the total drain output in Group A was $111.2 .2 \mathrm{ml}( \pm 86.78)$ and whereas mean output in Group B was $2184.2 \mathrm{ml}( \pm 140.06)$. p value was $<0.001$ showing a significant decrease in the total amount of the seroma fluid drained between the two groups.

The results of our study can be compared with a randomized controlled trial done by Faisal $\mathrm{M}$ et al ${ }^{9}$ on 64 patients that was carried out in Surgery Department, Suez Canal University Hospital, Ismailia, Egypt. Their results showed a significant reduction in the total amount of the drain output with the mean of the total amount in the study group after axillary exclusion $(1476.2 \mathrm{ml} \pm 518 \mathrm{ml})$ as compared to control group (4525.6 $\mathrm{ml} \pm 97.6 \mathrm{ml})$; $\mathrm{p}<0.001$.

In one study, Roman $\mathrm{M}$ et al. ${ }^{11}$ observed significant reduction in the amount of postoperative fluid formation and duration of drain placement in patients who had a breast conserving surgery as compared to those who had a modified radical mastectomy with Axillary dissection. Seroma is reportedly found in $15-81 \%$ of patients after axillary dissection. The most likely cause for the formation of seroma is the disruption of lymphatic channels in the axilla. It is supported by many studies. Petrek $e a^{12}$ in a prospective randomized trial exclaimed a significant influencing relation between the number and the extent of axillary lymph node involvement and formation of seroma. Similarly, with respect to extent of axillary dissection, an RCT of Purushotham et al ${ }^{16}$ has demonstrated that conventional axillary dissection is associated with significantly larger seroma formation as compared to sentinel LN biopsy.

In our study we have considered that there are 2 main factors contributing to postoperative seroma collection, first being the disruption of axillary lymphatics and the second is the dead space that forms in the axilla resulting from axillary dissection. So, it follows that excluding this space by closure from rest of wound might prove useful and the obliteration of dead spaces may result in improved recovery after surgery, as narrated by Halsted. ${ }^{8}$ Van Bemmel et allis also recommended the obliteration of dead space. Many studies have provided evidence that the technique used for axillary exclusion and axillary dead space obliteration by approximating the upper mastectomy flap to the pectoralis major muscle and lateral chest wall by continuous suture and suturing the pectoralis major to the pectoralis minor by interrupted sutures that was carried out in our study decreases postoperative seroma. Similar technique was used by A Khater et al in 2015, ${ }^{14}$ in A Randomized study and by ElSisi $e a l^{15}$ and they found that the total amount of fluid drained was significantly less $(\mathrm{P}<0.001$; highly significant) in both studies. Similarly N Chand et al ${ }^{10}$ has also demonstrated considerable reduction in post mastectomy drain output by separating the axillary space from the remainder of the mastectomy wound (reduction of over $65 \%, p<0.001$ ) and more importantly, significant reduction in formation of appreciable serous collections after removal of drain when the procedure of axillary exclusion is performed. ${ }^{9}$

However, the results of our study in agreement with other above studies justify the hypothesis of our study that "Axillary exclusion is an effective technique in reducing total drain outputs after Modified Radical Mastectomy in patients of Breast carcinoma."

\section{CONCLUSION}

We concluded that the axillary exclusion technique significantly reduces drain output and duration of drain placement in patients following modified radical mastectomy as compared to those who do not undergo axillary exclusion.

\section{LIMITATIONS}

Single center study with limited sample size.

\section{SUGGESTIONS / RECOMMENDATIONS}

We found the technique of axillary exclusion after modified radical mastectomy effective enough to reduce drain output and the duration before drain removal so that it may be recommended to apply in routine practice.

\section{CONFLICT OF INTEREST / DISCLOSURE}

No conflict of interests.

\section{ACKNOWLEDGEMENTS}

I would like to thank whole team surgical unit -I for their co-operation in data collection and completion of this study.

\section{REFERENCES}

1. Khan M. Effect of preoperative intravenous steroids on seroma formation after modified radical mastectomy. J Ayub Med Coll. Abbottabad. 2017;29(2):207-10.

2. Badar F, Faruqui ZS, Uddin N, Trevan EA. Management of Breast Lesions by Breast Physicians in a Heavily Populated South Asian Developing Country. Asian Pac J Cancer Prev. 2011;12(3):827-32

3. Sutter S, Slinker A, Balumuka D, Mitchell K. Surgical management of breast cancer in Africa A continent-wide review of intervention practices, barriers to care, and adjuvant therapy. J Global Oncol. 2017;3:162-8. 
4. Stoyanov G, Tsocheva D, Marinova K, Dobrev E, Nenkov R. Drainage after modified radical mastectomy - A methodological mini-review. Cureus. 2017;9(7):1454

5. Turner EJ, Benson JR, Winters ZE. Techniques in the prevention and management of seromas after breast surgery. Future Oncol. 2014;10(6):1049-63.

6. Srivastava V, Basu S, Shukla VK, Seroma formation after breast cancer surgery: what we have learned in the last two decades. J Breast Cancer. 2012;15(4):373-80.

7. Kuroi K, Shimozuma K, Taguchi T, Imai H, Yamashiro H, Ohsumi $\mathrm{S}$, Saito S. Evidence-based risk factors for seroma formation in breast surgery. Jpn J Clin Oncol. 2006;36(4):197-206

8. Benevento R, Santoriello A, Pellino G, Sciaudone G, Candilio G, De Fatico $\mathrm{G}$ et al. The effects of low-thrombin fibrin sealant on wound serous drainage, seroma formation and length of postoperative stay in patients undergoing axillary node dissection for breast cancer. A randomized controlled trial. Int J Surg. 2014;12(11):12105.

9. Faisal M, Abu-Elela S, Mostafa W, Antar O. Efficacy of axillary exclusion on seroma formation after modified radical mastectomy. World J Surg Oncol. 2016;14(1):1-5.

10. Chand N, Aertssen A.M.G, Royle G.T. Axillary "exclusion" - A successful technique for reducing seroma formation after mastectomy and axillary dissection. Adv Breast Cancer Res. 2013;2(1):1-6.
11. Roman M, Nogaret JM, Fils JF, Bourgeois P. Seromas and Punctures after Complete Axillary Node Dissection for Breast Cancer: Differences between Mastectomy and Lumpectomy. J Surgery. 2015;3(2):7.

12. Sakkary MA. The value of mastectomy flap fixation in reducing fluid drainage and seroma formation in breast cancer patients. World J Surg Oncol. 2012;10:8

13. Van Bemmel AJ, van de Velde CJ, Schmitz RF, Liefers GJ. Prevention of seroma formation after axillary dissection in breast cancer: A systematic review. Eur J Surg Oncol 2011;37(10):829-35.

14. Khater A, Elnahas W, Roshdy S, Farouk O, Senbel A, Fathi A et al. Evaluation of the Quilting technique for reduction of postmastectomy seroma: A randomized controlled study. Int J Breast Cancer. 2015;2015:1-6.

15. El-Sisi AA, Mohamed AMF, Amer NF. Dead space obliteration for reducing seroma formation after mastectomy and axillary dissection. Menoufia Med J. 2015;28(1):69-73.

16. Purushotham AD, Upponi S, Klevesath MB, Bobrow L, Millar K, Myles JP, et al. Morbidity after sentinel lymph node biopsy in primary breast cancer: results from a randomized controlled trial. J Clin Oncol 2005;23(19):4312-21.

17. Irfan S, Akram M, Rehman S, Sajid M. Clinicopathological Pattern of Breast Cancer Presentation in Allied Hospital Faisalabad. APMC 2019;13(1):30-2. 